\title{
Colorectal endoscopic submucosal dissection using "mucosal bridges" for local recurrence after endoscopic resection
}

Endoscopic submucosal dissection (ESD) for local recurrence after endoscopic resection can be challenging because of diffuse submucosal fibrosis. Although the pocket-creation method (PCM) is very useful to overcome submucosal fibrosis during colorectal ESD [1-3], identifying the dissecting line amidst diffuse fibrotic submucosa is difficult because the edge of the resected specimen is invisible from inside the pocket. Here, we present a novel strategy for performing ESD using mucosal bridges ( $>$ Fig. 1, - Video 1).

A 59-year-old woman was diagnosed with a laterally spreading tumor located over the scar of a previous endoscopic mucosal resection in the proximal rectum. The procedure was initiated in the same manner as that for PCM, and thereafter a circumferential incision was made leaving a mucosal margin of several millimetres on both sides of the pocket entrance as mucosal bridges. Submucosal dissection was performed on the lateral sides creating a "V-shaped" tunnel with two exits. The dissecting line could be targeted even in the presence of fibrotic submucosa to connect the two exits of the "V-shaped" tunnel, with sufficient traction provided by the mucosal bridges ( $\triangleright$ Fig.2). The lesion was resected completely, and histological examination revealed a high grade adenoma with $\mathrm{R} 0$ resection.

In this case, we could identify the dissecting line by making a "V-shaped" tunnel. The two exits can also serve as drainage outlets for the pooled water or blood in the pocket during submucosal dissection. Mucosal bridges provide sufficient traction and stable maneuverability, and are effective until the latter phase of the procedure. The advantage of this novel strategy using mucosal bridges is that one can switch to it from PCM, even halfway through the submucosal dissection, depending on factors such as submucosal fibrosis, endoscopic approach, and

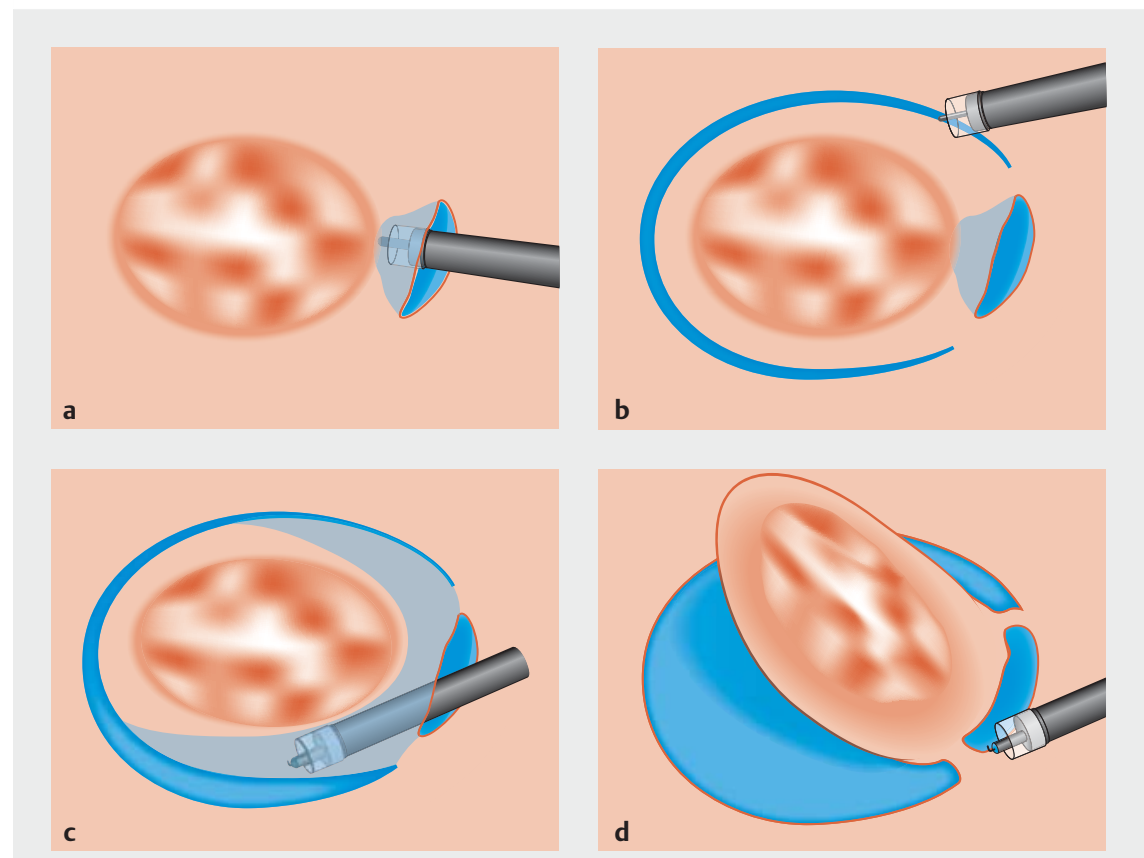

- Fig. 1 The sequence of endoscopic submucosal dissection using mucosal bridges. a Initial mucosal incision at the distal side of the lesion and creation of a submucosal pocket. b Nearcircumferential incision, keeping two mucosal bridges. c Submucosal dissection inside the "V-shaped" tunnel. $\mathbf{d}$ Cutting the mucosal bridges and completion of en bloc resection.
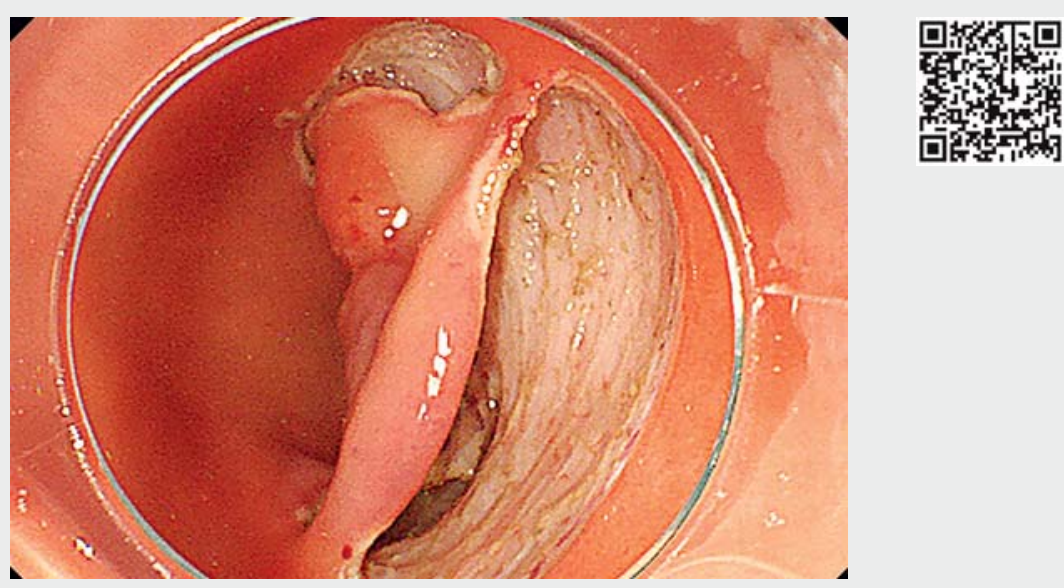

$\checkmark$ Video 1 Endoscopic submucosal dissection using mucosal bridges for a rectal laterally spreading tumor. 


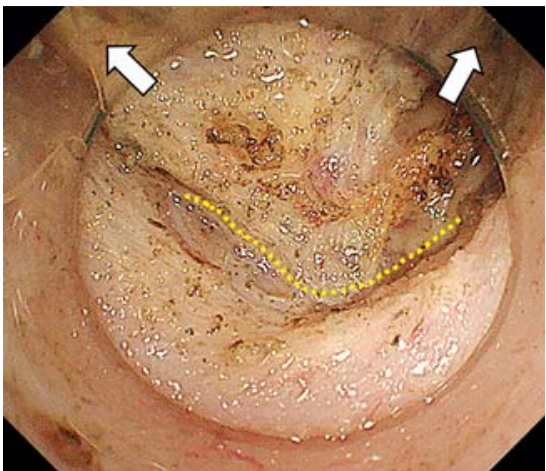

- Fig. 2 Endoscopic view during submucosal dissection using mucosal bridges. White arrows show the direction of mucosal bridge traction. Yellow dotted line shows dissecting line.

maneuverability. The adaptability of this strategy to the situation during the procedure can be considered favorable for colorectal ESD.

Endoscopy_UCTN_Code_TTT_1AO_2AG

Competing interests

None
The authors

Shunsuke Yoshii, Yoshito Hayashi, Yoshik Tsujii, Hideki lijima, Tetsuo Takehara Department of Gastroenterology and Hepatology, Osaka University Graduate School of Medicine, Osaka, Japan

\section{Corresponding author}

\section{Tetsuo Takehara, MD, PhD}

Department of Gastroenterology and Hepatology, Osaka University Graduate School of Medicine, Osaka, Japan

Fax: +81-6-68793629

takehara@gh.med.osaka-u.ac.jp

\section{References}

[1] Hayashi Y, Sunada K, Takahashi H et al. Pocket-creation method of endoscopic submucosal dissection to achieve en bloc resection of giant colorectal subpedunculated neoplastic lesions. Endoscopy 2014; 46 (Suppl. 01): E421-E422

[2] Yoshida N, Naito Y, Yasuda R et al. The efficacy of the pocket-creation method for cases with severe fibrosis in colorectal endoscopic submucosal dissection. Endosc Int Open 2018; 6: E975-E983
[3] Shinozaki S, Hayashi Y, Lefor AK et al. What is the best therapeutic strategy for colonoscopy of colorectal neoplasia? Future perspectives from the East. Dig Endosc 2016; 28: $289-295$

\section{Bibliography}

DOI https://doi.org/10.1055/a-0889-7230

Published online: 9.5.2019

Endoscopy 2019; 51: E241-E242

(c) Georg Thieme Verlag KG

Stuttgart · New York

ISSN 0013-726X

\section{ENDOSCOPY E-VIDEOS \\ https://eref.thieme.de/e-videos}

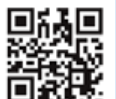

Endoscopy E-Videos is a free access online section, reporting on interesting cases and new techniques in gastroenterological endoscopy. All papers include a high quality video and all contributions are freely accessible online.

This section has its own submission website at https://mc.manuscriptcentral.com/e-videos 